\title{
CAPACITY BUILDING FOR POST-DISASTER INFRASTRUCTURE DEVELOPMENT AND MANAGEMENT
}

\author{
Guest Editors \\ Dr Richard HAIGH \\ and Professor Dilanthi AMARATUNGA \\ School of the Built Environment, \\ University of Salford, UK
}




\section{Guest Editorial}

\section{CAPACITY BUILDING FOR POST-DISASTER INFRASTRUCTURE DEVELOPMENT AND MANAGEMENT}

\section{Richard HAIGH and Dilanthi AMARATUNGA}

School of the Built Environment, The University of Salford, Maxwell Building - $4^{\text {th }}$ Floor, Salford, Greater Manchester, M5 4WT, UK

E-mail: R.D.G.Amaratunga@salford.ac.uk; R.P.Haigh@salford.ac.uk

In June 2008, the European Commission funded EURopean and ASian Infrastructure Advantage (EURASIA) project led a special session at The International Symposium on Automation and Robotics in Construction (ISARC 2008), held in Vilnius, Lithuania. EURASIA was a three year project that aimed to improve capacity in training, teaching and research activities associated with the creation and long-term management of public and commercial facilities and infrastructure in selected Higher Education Institutes in Asia and Europe. The EURASIA partners included the University of Moratuwa and University of Ruhuna in Sri Lanka, the University of Salford in the UK, Tallinn University of Technology in Estonia, and Vilnius Gediminas Technical University in Lithuania.

The special session focused on the challenge of building capacity to support mitigation and preparedness activities prior to a disaster, and for response and reconstruction activities in the event of disaster occurring. In recent years, there has been increasing recognition of the contribution that built environment related professionals can make towards increasing a community's resilience to disasters. The 'built environment' encompasses a wide variety of professional expertise including design, construction management, quantity surveying, building surveying, and property man- agement. Their contribution occurs beyond the traditional cycle of feasibility analysis, planning, design, construction, operation, maintenance and divestiture, to encompass the built environment professional's ability to anticipate and respond to unexpected events that damage or destroy a building or infrastructure project, and reflect an ongoing responsibility towards the host community.

The origins of the term 'capacity building' are often associated with the beginning of the modern era of international development cooperation during the 1950 s. Efforts of capacity building in this period focused on two main areas: completing basic institutional infrastructure in countries and improving the ability of development organisations to implement donor funded projects. In this context the emphasis appears to be on international activity and intervention by an organisation in one country to help those in another. More recent definitions broaden the scope away from just international activity and development policy objectives. The United Nations Development Programme defines 'capacity building' as, "the creation of an enabling environment with appropriate policy and legal frameworks, institutional development, including community participation, human resources development and strengthening of managerial systems." The CIB (the International Council for Research 
and Innovation in Building and Construction), in support of its initiative on building capacity for disaster reconstruction, puts forward capacity building as the ability of central and local government, non state actors and the private sector, individuals and communities, to identify constraints and to plan and manage reconstruction of the built environment after a disaster effectively, efficiently and sustainably. This definition involves both the development of human resources, institutions, and communities, and also a supportive policy environment. It encompasses the process by which individuals, communities and institutions develop, utilise and retain their skills, abilities and knowledge individually and collectively, to identify their problems and constraints, set reconstruction objectives, formulate policies and programs, perform functions required to solve those problems, and achieve a set of reconstruction objectives.

The present issue of the International Journal of Strategic Property Management draws on the wide range of expertise that built environment professionals can contribute towards increasing our capacity to develop resilience to disasters. It compiles original papers which were prepared for a panel of The International Symposium on Automation and Robotics in Construction - ISARC, 2008. The papers demonstrate the wide range of capacity building related challenges and solutions, and stretch across the disaster management lifecycle, from pre-disaster risk reduction, through to postdisaster response and relief, and finally, long term sustainable reconstruction.

Perera and co-authors discuss risk as an unavoidable phenomenon in construction projects. Proper risk allocation in construction contracts has therefore come to assume prominence because risk identification and risk allocation have a clear bearing on risk handling decisions. The proper management of risks requires that they be identified and allocated in a well-defined manner. This can only be achieved if contracting parties comprehend their risk responsibilities, risk event conditions, and risk handling capabilities. The authors present research that identifies the risk responsibilities of contractual parties in order to improve their risk handling strategies with regard to Sri Lankan road projects. The results show that road construction projects in Sri Lanka are exposed to many risk sources while most risks are borne by parties who were assigned with risks via contract clauses. The authors conclude that there is no one best way to respond to a risk and that different risk handling strategies should be adopted in order to deal effectively with risks.

Enoma and co-authors examine airport redesign for enhanced safety and security in three Scottish Airports. In particular, they explore the role of Facilities Management (FM) in improving safety and security at airports and consider the link between FM and design. The authors consider the complete journey circle from airport to aircraft and from aircraft back to the airport. They conclude that planning for safety and security are airport specific: each airport requires a bespoke solution according to its size, mode of operations, passenger type and flight destinations.

Kaklauskas and co-authors present research that aims to help post-disaster managers find the most rational solutions by using advanced knowledge models. The authors describe the development of a knowledge model for post-disaster management based upon multiple criteria decision making theory. The developed model involves six stages that help to determine rational post-disaster management alternatives by evaluating the post-disaster management life cycle, stakeholders, and the micro and macro environment.

In a similar vein, Keraminiyage and coauthors contend that due to the globalisation of the research agenda, exemplified by 
research into disaster management, the concept of Virtual Research Environments (VRE) has emerged to assist the research community to address the complex challenges associated with conducting collaborative research. The authors describe the development of a VRE to support a multi-partner international research project on disaster management and present a model to evaluate the custom built VRE using well known Computer Human Interaction principles.

The latter three papers focus upon capacity building in the post-disaster phase. Rotimi and co-authors investigate the recovery process in New Zealand in terms of how legislation either facilitates or hinders reconstruction projects and programmes. The authors consider legislation that applies to routine construction to provide for the safe development of infrastructure, capital improvements and land use, ensuring preservation and environmental protection. The authors conclude that the New Zealand Building Act 2004 will not be supportive or enabling in post-disaster reconstruction environments, particularly in large-scale disaster events. The results show that there remain challenges in meeting reconstruction objectives both efficiently and effectively under the Act.

Lawther focuses on the community involvement in post disaster reconstruction as an important ingredient to the overall success of housing and infrastructure redevelopment. Lawler argues that implementing agencies and governments need to design post disaster reconstruction programs which promote the involvement of beneficiaries and communities, to the extent allowed by the scale and context of any given situation. By extension, management and organisational capacities which enable community involvement in the post disaster reconstruction projects need to be identified and developed to facilitate this process. A British Red Cross Maldives post - tsunami recovery program is presented as a case study.
Through this, Lawler identifies successes, limitations, and lessons learnt. The case study is examined to identify capacity building opportunities for community involvement in future post disaster reconstruction projects.

Finally, Karunasena and co-authors focus on the environmental and economic burden on normal living conditions, reconstruction and general waste collection processes following a disaster. The authors demonstrate that waste management has emerged as a critical issue in the response and long term reconstruction phases of a disaster, and examine post-disaster waste management strategies adopted in developing countries and the applicability of best practices. The study reveals that the strategies, issues and challenges associated with waste management vary according to the type of disaster, magnitude, location, and country. The authors conclude that poor implementation of prevailing rules and regulations, poor standards of local expertise and capacities, inadequate funds, and a lack of communication and coordination are the main challenges to be overcome.

The Editors are grateful for the contribution of the Special Issue Editorial Board:

Prof Les Ruddock, University of Salford, UK.

Prof Arturas Kaklauskas, Vilnius Gediminas Technical University, Lithuania.

Mr Kushan Kulatunga, Corderoy, UK.

Ms Roshani Palliyaguru, University of Salford, UK.

Dr Bingu Ingirige, University of Salford, UK.

Professor Irene Lill, Tallinn University of Technology, Estonia.

Dr Shu-Ling Lu, University of Salford, UK.

Dr Chaminda Pathirage, University of Salford, UK.

Dr Clive Warren, University of Queensland, Australia. 
Mr Kaushal Keraminiyage, University of Salford, UK.

Dr Udayangani Kulatunga, University of Salford, UK.

Ms Nirooja Thurairajah, University of Salford, UK.

This special issue of the International Journal of Strategic Property Management is our contribution to developing the capacity of soci- ety to prepare for and respond to disasters. It contributes to increasing our understanding of the built environment professions' role in disaster mitigation, response and reconstruction. Hopefully many more studies will build on this contribution and encourage the built environment community to engage with relevant stakeholders in order to enhance our capacity to deal with this challenging and complex problem. 